\title{
Orthostatic hypotension: prevalence and associated risk factors among the ambulatory elderly in an Asian population
}

Qing Olivia $\underline{Z h u^{1}}$, MBBs, Choon Seng Gilbert $\underline{T a n}^{2}$, MMed, FCFPS, Hwee Leong $\underline{\operatorname{Tan}}^{1}$, MBBS, Ruining Geraldine $\underline{\text { Wong }}^{1}$, MBBS, Chinmaya Shrikant $\underline{\text { Joshi }}^{1}$, MBBS, Ravi Amran Cuttilan ${ }^{1}$, MBBS, Gek Khim Judy $\underline{S n g}^{3}$, MBBS, MMed, Ngiap Chuan $\underline{\operatorname{Tan}}^{4,5}$, MMed, FCFPS

INTRODUCTION The prevalence of orthostatic hypotension $(\mathrm{OH})$ among the elderly population in Singapore, as defined by a decline in blood pressure upon a change in position, is not well-established. Studies associate $\mathrm{OH}$ with clinically significant outcomes such as falls. This study aims to determine the prevalence of $\mathrm{OH}$ among elderly patients attending a public primary care clinic (polyclinic) for chronic disease management, and examine the relationships between postulated risk factors and $\mathrm{OH}$.

METHODS Patients aged $\geq 65$ years attending a typical polyclinic in Geylang were identified and targeted for recruitment at the study site. A questionnaire on symptoms and postulated risk factors was administered, followed by supine and standing blood pressure measurements. Cross-sectional analysis was performed with independent sample $t$-test for continuous data and chi-square test for categorical data. Prevalence rate ratios with $95 \%$ confidence interval were calculated for the latter.

RESULTS A total of 364 multiethnic patients participated in the study. The prevalence of $\mathrm{OH}$ was $11.0 \%$. Older age, comorbidities such as cardiac failure and kidney disease, being physically inactive at work, fatigue, self-reported dizziness in the past year, and the use of loop diuretics were found to be significantly associated with $\mathrm{OH}$.

CONCLUSION About one in ten elderly patients at a local polyclinic was affected by $\mathrm{OH}$, which was associated with multiple factors. Some of these factors are modifiable and can be addressed to reduce the incidence of $\mathrm{OH}$.

Keywords: elderly, orthostatic hypotension, prevalence, primary care

\section{INTRODUCTION}

The 1996 consensus statement by the Consensus Committee of the American Autonomic Society and the American Academy of Neurology $y^{(1,2)}$ defines orthostatic hypotension $(\mathrm{OH})$ as a drop in systolic blood pressure $\geq 20 \mathrm{mmHg}$ or diastolic blood pressure $\geq 10 \mathrm{mmHg}$ within three minutes of standing from a supine or seated position. ${ }^{(3-5)} \mathrm{OH}$ is a well-established clinical entity $^{(6-8)}$ that is associated with a wide range of morbidities in the literature, such as cardiovascular disease, cognitive decline and an increased risk of falls. ${ }^{(4,5,9-11)}$ Despite this, its current prevalence among the local elderly population attending primary healthcare settings is not well-established. The first set of data collected locally in 1987 suggested a prevalence of $22 \%$ in a hospitalised population. ${ }^{(12)}$ Another sub-analysis in a longitudinal study in 1999 showed a prevalence of $16.6 \%$ in a communitydwelling Chinese population aged 55 years and above, but did not include patients with comorbidities such as previous stroke and cardiovascular diseases. ${ }^{(5)}$ Overseas population studies provided wide variations in estimates of $\mathrm{OH}$ prevalence ranging from $5 \%$ to $34 \%$. The variation is attributable to the different demographic characteristics and settings of study populations. ${ }^{(13)}$

The magnitude of $\mathrm{OH}$ and understanding of its associated risk factors has an impact on the design of screening programmes, clinical practice and health service delivery to the geriatric population in the local community. Thus, the primary objective of this study was to determine the prevalence of $\mathrm{OH}$ among elderly patients aged $\geq 65$ years (an accepted definition of old age in most developed countries) ${ }^{(14)}$ who attended a typical public primary care clinic (i.e. polyclinic) in Singapore. The secondary objective of this study was to assess the associations between $\mathrm{OH}$ and various clinical and non-clinical factors. Such information would allow us to identify factors that can increase the risk of $\mathrm{OH}$, so that appropriate measures can be introduced to mitigate associated adverse outcomes in at-risk patients.

\section{METHODS}

The study was conducted over two weeks in February 2013. Participants attended SingHealth Polyclinics-Geylang, a typical public primary care clinic located in the mideastern part of Singapore. Elderly patients aged $\geq 65$ years constituted about $27 \%$ of the clinic's 700-900 daily patient attendance in 2014 (according to unpublished data). Our target group consisted of community-dwelling, multiethnic Asian elderly adults who were ambulatory; aged $\geq 65$ years and above; and managed at the study site for their existing chronic medical conditions, such as diabetes mellitus, hypertension and hyperlipidaemia. The exclusion

${ }^{1} \mathrm{MOH}$ Holdings Private Limited, ${ }^{2} \mathrm{Clinical}$ and Corporate Services, Sing Health Polyclinics, ${ }^{3}$ Saw Swee Hock School of Public Health, National University of Singapore, ${ }^{4}$ Department of Research, Sing Health Polyclinics, ${ }^{5}$ Duke-NUS Medical School, Singapore

Correspondence: Dr Tan Choon Seng Gilbert, Senior Consultant, Clinical and Corporate Services, SingHealth Polyclinics, 167 Jalan Bukit Merah, Tower 5, \#15-10, Singapore 150167.gilbert.tan.c.s@singhealth.com.sg 
criteria included: (a) non-ambulatory, including wheelchairbound, patients; ${ }^{(15)}$ (b) those who were unable to give verbal and written informed consent, and had no legal representative present; and (c) those who presented with acute conditions during the recruitment period, for whom blood pressure measurements could not be taken.

All eligible patients were provided with information sheets to help them understand the study. Research assistants were present to explain the study protocol and clarify any queries before written informed consent was obtained. The study protocol was approved by the SingHealth Centralised Institutional Review Board (CIRB Ref 2013/014/E).

The highest reported prevalence rate of $\mathrm{OH}$, as identified from our literature review, was used to calculate the target sample size. The upper limit of the range of prevalence rates obtained from our literature review was $34 \%$ in a population of home-dwelling elderly $\geq 75$ years of age in Finland. ${ }^{(16)}$ Using the above prevalence, at a 95\% confidence interval $(\mathrm{Cl})$ and margin of error of $5 \%$, we calculated an estimated sample size of 400 (taking into account a buffer of $20 \%$ ). ${ }^{(17)}$

A systematic approach was used for patient recruitment. During clinic registration, patients who met the inclusion criteria were 'tagged' with a sticker on their queue slip. Each 'tagged' patient, identified by the sticker, was placed into one of three categories: (a) patients who were ineligible as they met at least one exclusion criteria; (b) those who were eligible and consented ('responders'); and (c) those who were eligible but did not consent ('non-responders'). Responders were taken to designated rooms where the study questionnaire was administered and postural blood pressure measurements were taken, prior to consultation with their respective doctors. The risk of double-counting the number of patients identified as responders and non-responders was minimised via specific labelling of the stickers on their queue slips to indicate that they had previously been approached and their response recorded.

Trained interviewers conducted face-to-face interviews with the responders using a standardised script. Apart from basic demographic information such as age, gender, race, height and weight, ${ }^{(18)}$ the presence of symptoms of interest based on the literature review was also sought. These included lightheadedness or dizziness, syncope, headache, visual disturbances, neck or chest discomfort, palpitations, nausea, and generalised weakness experienced both during the measurement of postural blood pressure as well as over the previous year prior to the study. ${ }^{(19)}$ Selected aspects of the patients' social history were also assessed, including their physical activity at work or during recreation, ambulatory status, ${ }^{(3)}$ history of falls, ${ }^{(8,9)}$ alcohol intake, ${ }^{(18)}$ caffeine intake, and smoking history.

Calibrated DINAMAP $®$ blood pressure (BP) machines (Procare 100; GE Healthcare, Little Chalfont, Buckinghamshire, UK) currently in use in the clinic were used to measure the blood pressure of all participants throughout the study. BP and pulse rates were recorded from the right arm three times after (a) resting supine for five minutes; (b) standing unaided for one
Table I. Demographic profiles of the overall study population $(n=364)$.

\begin{tabular}{lc}
\hline Characteristic & No. (\%) \\
\hline Gender & $180(49.5)$ \\
Male & $184(50.5)$ \\
Female & \\
Ethnicity & $317(87.1)$ \\
Chinese & $28(7.7)$ \\
Malay & $16(4.4)$ \\
Indian & $3(0.8)$ \\
Others & $74.6(64.1-98.0)$ \\
\hline Age* (yr) &
\end{tabular}

*Data presented as mean (range)

minute; and (c) standing unaided for three minutes. If either BP reading during erect posture at one or three minutes showed a reduction of systolic blood pressure $\geq 20 \mathrm{mmHg}$ or diastolic blood pressure $\geq 10 \mathrm{mmHg}$, the patient would qualify as having postural hypotension. Measures were in place to ensure patients' safety. They were told to inform the investigator immediately upon experiencing any symptoms possibly relating to $\mathrm{OH}$. Patients who were unable to stand during the study for any reason had their BP taken while they sat upright unaided.

Patients' responses were recorded on serially numbered questionnaire forms. The data was then anonymised and analysed using IBM SPSS Statistics version 19.0 (IBM Corp, Armonk, NY, USA). Independent sample $t$-test was used to analyse the association between $\mathrm{OH}$ and various factors for continuous data, and chi-square test was used for categorical data. Prevalence rate ratios and their corresponding 95\% Cls were calculated for categorical data analysis.

\section{RESULTS}

A total of 668 patients were eligible for participation, based on age alone, over the recruitment period of four days. We were able to approach 597 (89.4\%) patients in the waiting areas of the study site. 511 patients fulfilled the inclusion criteria; of these, $364(71.2 \%)$ patients consented to and completed the study. Their demographic profiles are shown in Table I.

About one in ten patients in our study $(\mathrm{n}=40)$ were found to have $\mathrm{OH}$, giving a prevalence rate of $11.0 \%(95 \% \mathrm{Cl} 8.2-14.8)$. Higher proportions of older patients (i.e. aged $>70$ years) and patients who were not physically active at work were found to be associated with $\mathrm{OH}$ (Table II). $\mathrm{OH}$ was also associated with symptoms of fatigue during postural blood pressure measurement and lightheadedness/dizziness experienced in the past year (Table III).

Patients with comorbidities such as congestive cardiac failure, stroke and chronic renal disease (also known as kidney disease) were more likely to experience $\mathrm{OH}$. The list of chronic renal diseases was based on a specified diagnosis list of renal diseases in the electronic health records of the participants, such as renal failure, glomerular nephritis, nonspecific nephritis and nephropathy. For medications, patients who were on loop diuretics were more likely to have $\mathrm{OH}$ (Table IV). 
Table II. Demographics, social factors and functional status by orthostatic hypotension $(\mathrm{OH}) \mathrm{status}(\mathrm{n}=\mathbf{3 6 4})$.

\begin{tabular}{|c|c|c|c|}
\hline \multirow[t]{2}{*}{ Characteristic } & \multicolumn{2}{|c|}{ No. (\%) } & \multirow{2}{*}{$\begin{array}{c}\text { Prevalence rate } \\
\text { ratio }(95 \% \mathrm{CI})\end{array}$} \\
\hline & With OH $(n=40)$ & Without OH $(n=324)$ & \\
\hline \multicolumn{4}{|l|}{ Age (yr) } \\
\hline$\leq 70$ & $5(4.9)$ & $97(95.1)$ & 1 \\
\hline$>70$ & $35(13.4)$ & $227(86.6)$ & $2.73(1.10-6.67)^{\ddagger}$ \\
\hline \multicolumn{4}{|l|}{ Gender } \\
\hline Male & $14(7.8)$ & $166(92.2)$ & 1 \\
\hline Female & $26(14.1)$ & $158(85.9)$ & $1.81(0.98-3.33)$ \\
\hline \multicolumn{4}{|l|}{ Ethnicity } \\
\hline Non-Chinese & $8(17.0)$ & $39(83.0)$ & 1 \\
\hline Chinese & $32(10.1)$ & $285(89.9)$ & $0.59(0.29-1.21)$ \\
\hline \multicolumn{4}{|l|}{ Social factor } \\
\hline \multicolumn{4}{|c|}{ Consumes alcohol* } \\
\hline No & $34(11.0)$ & $276(89.0)$ & 1 \\
\hline Yes & $5(9.4)$ & $48(90.6)$ & $0.86(0.35-2.10)$ \\
\hline \multicolumn{4}{|c|}{ Current smoker } \\
\hline No & $37(11.3)$ & $290(88.7)$ & 1 \\
\hline Yes & $3(8.1)$ & $34(91.9)$ & $0.72(0.23-2.21)$ \\
\hline \multicolumn{4}{|c|}{ Consumes caffeinated beverages* } \\
\hline No & $6(14.6)$ & $35(85.4)$ & 1 \\
\hline Yes & $33(10.2)$ & $289(89.8)$ & $0.70(0.31-1.57)$ \\
\hline \multicolumn{4}{|c|}{ Functional status } \\
\hline \multicolumn{4}{|c|}{ Physically active at work* } \\
\hline No & $37(12.5)$ & $260(87.5)$ & 1 \\
\hline Yes & $2(3.0)$ & $64(97.0)$ & $0.24(0.06-0.98)^{*}$ \\
\hline \multicolumn{4}{|c|}{ Physically active in leisure/recreation* } \\
\hline No & $10(8.3)$ & $111(91.7)$ & 1 \\
\hline Yes & $29(12.0)$ & $213(88.0)$ & $1.46(0.73-2.87)$ \\
\hline \multicolumn{4}{|c|}{ Needs to climb stairs in daily life ${ }^{\dagger}$} \\
\hline No & $30(12.0)$ & $219(88.0)$ & 1 \\
\hline Yes & $10(8.8)$ & $104(91.2)$ & $0.73(0.37-1.44)$ \\
\hline \multicolumn{4}{|c|}{ Presence of daily caregiver ${ }^{+}$} \\
\hline No & $33(10.6)$ & $279(89.4)$ & 1 \\
\hline Yes & $7(14.0)$ & $43(86.0)$ & $1.32(0.62-2.82)$ \\
\hline \multicolumn{4}{|c|}{ Needs walking aids at home ${ }^{+}$} \\
\hline No & $35(10.4)$ & $303(89.6)$ & 1 \\
\hline Yes & $5(20.8)$ & $19(79.2)$ & $2.01(0.87-4.67)$ \\
\hline \multicolumn{4}{|c|}{ Needs walking aids in the community ${ }^{+}$} \\
\hline No & $30(10.4)$ & $258(89.6)$ & 1 \\
\hline Yes & $10(13.7)$ & $63(86.3)$ & $1.32(0.68-2.57)$ \\
\hline
\end{tabular}

* Numbers do not add up to $n=40$ due to missing data. ${ }^{\dagger}$ Numbers do not add up to $n=324$ due to missing data. ${ }^{2}$ Difference is statistically significant ( $p<0.05$ ). $\mathrm{Cl}$ : confidence interval

\section{DISCUSSION}

Singapore faces a rapidly greying population; the number of Singapore citizens and permanent residents aged $\geq 65$ years grew by $6.5 \%$ to 459,700 in $2015 .{ }^{(20)}$ The $11.0 \% \mathrm{OH}$ prevalence found in our study compares well with other studies that reported rates of $15.9 \%-16.6 \%$ and $6.1 \% .{ }^{(6,21)}$ The Finnish study reported a markedly higher prevalence rate of $34.0 \%$, which could be related to differences in study population and methodology. ${ }^{(16)}$

The finding that age was a factor in $\mathrm{OH}$ is consistent with the results of several studies in the literature. ${ }^{(6,18,22)}$ Notably, our study did not find an association between ethnicity and the presence of $\mathrm{OH}$. The number of participants of non-Chinese origin in this study may have been insufficient to show a significant difference. This factor requires further research using a sampling frame stratified by ethnicity. We also found that individuals who were physically active at work were less likely to be associated with $\mathrm{OH}$ compared to those who were inactive. Physical activity at work may promote better physical conditioning and activity outside the home environment, and hence a lower likelihood of having $\mathrm{OH}$. This is consistent with previous reports of homebound status as a risk factor for $\mathrm{OH} .{ }^{(16)}$ Fatigue and lightheadedness, 
Table III. Self-reported symptoms associated with orthostatic hypotension $(\mathrm{OH})(\mathrm{n}=364)$.

\begin{tabular}{|c|c|c|c|}
\hline \multirow[t]{2}{*}{ Symptom } & \multicolumn{2}{|c|}{ No. (\%) } & \multirow{2}{*}{$\begin{array}{l}\text { Prevalence rate } \\
\text { ratio }(95 \% \mathrm{Cl})\end{array}$} \\
\hline & With OH $(n=40)$ & Without OH $(n=324)$ & \\
\hline \multicolumn{4}{|c|}{ During postural BP measurement } \\
\hline \multicolumn{4}{|c|}{ Lightheadedness/dizziness } \\
\hline No & $37(11.1)$ & $297(88.9)$ & 1 \\
\hline Yes & $3(10.0)$ & $27(90.0)$ & $0.90(0.30-2.75)$ \\
\hline \multicolumn{4}{|c|}{ Visual disturbances } \\
\hline No & $40(11.3)$ & $313(88.7)$ & 1 \\
\hline Yes & 0 & $11(100.0)$ & $0.40(0.03-6.07)$ \\
\hline \multicolumn{4}{|c|}{ Neck discomfort } \\
\hline No & $38(10.8)$ & $313(89.2)$ & 1 \\
\hline Yes & $2(15.4)$ & $11(84.6)$ & $1.42(0.38-5.26)$ \\
\hline \multicolumn{4}{|c|}{ Chest discomfort } \\
\hline No & $40(11.0)$ & $322(89.0)$ & 1 \\
\hline Yes & 0 & $2(100.0)$ & $4.51(0.62-32.68)$ \\
\hline \multicolumn{4}{|c|}{ Palpitations } \\
\hline No & $39(10.9)$ & $319(89.1)$ & 1 \\
\hline Yes & $1(16.7)$ & $5(83.3)$ & $1.53(0.25-9.35)$ \\
\hline \multicolumn{4}{|l|}{ Fatigue } \\
\hline No & $36(10.3)$ & $313(89.7)$ & 1 \\
\hline Yes & $4(26.7)$ & $11(73.3)$ & $2.58(1.06-6.33)^{*}$ \\
\hline \multicolumn{4}{|l|}{ Syncope } \\
\hline No & $40(11.0)$ & $324(89.0)$ & 1 \\
\hline Yes & 0 & 0 & $4.51(0.62-32.68)$ \\
\hline \multicolumn{4}{|c|}{ Generalised weakness } \\
\hline No & $37(10.5)$ & $314(89.5)$ & 1 \\
\hline Yes & $3(23.1)$ & $10(76.9)$ & $2.19(0.78-6.17)$ \\
\hline \multicolumn{4}{|l|}{ Nausea } \\
\hline No & $40(11.0)$ & $322(89.0)$ & 1 \\
\hline Yes & 0 & $2(100.0)$ & $4.51(0.62-32.68)$ \\
\hline \multicolumn{4}{|c|}{ In past $1 \mathrm{yr}$} \\
\hline \multicolumn{4}{|c|}{ Lightheadedness/dizziness } \\
\hline No & $20(7.8)$ & $236(92.2)$ & 1 \\
\hline Yes & $20(18.5)$ & $88(81.5)$ & $2.37(1.33-4.22)^{*}$ \\
\hline \multicolumn{4}{|c|}{ Visual disturbances } \\
\hline No & $35(11.5)$ & $269(88.5)$ & 1 \\
\hline Yes & $5(8.3)$ & $55(91.7)$ & $0.72(0.30-1.77)$ \\
\hline \multicolumn{4}{|c|}{ Neck discomfort } \\
\hline No & $30(10.6)$ & $254(89.4)$ & 1 \\
\hline Yes & $10(12.5)$ & $70(87.5)$ & $1.18(0.60-2.31)$ \\
\hline \multicolumn{4}{|c|}{ Chest discomfort } \\
\hline No & $36(11.2)$ & $286(88.8)$ & 1 \\
\hline Yes & $4(9.5)$ & $38(90.5)$ & $0.85(0.32-2.27)$ \\
\hline \multicolumn{4}{|c|}{ Palpitations } \\
\hline No & $35(10.9)$ & $287(89.1)$ & 1 \\
\hline Yes & 5 (11.9) & $37(88.1)$ & $1.10(0.45-2.64)$ \\
\hline \multicolumn{4}{|l|}{ Fatigue } \\
\hline No & $28(10.4)$ & $240(89.6)$ & 1 \\
\hline Yes & $12(12.5)$ & $84(87.5)$ & $1.20(0.63-2.26)$ \\
\hline \multicolumn{4}{|l|}{ Syncope } \\
\hline No & $38(10.7)$ & 317 (89.3) & 1 \\
\hline Yes & $2(22.2)$ & $7(77.8)$ & $2.07(0.59-7.30)$ \\
\hline
\end{tabular}




\begin{tabular}{|c|c|c|c|}
\hline \multirow[t]{2}{*}{ Symptom } & \multicolumn{2}{|c|}{ No. (\%) } & \multirow{2}{*}{$\begin{array}{l}\text { Prevalence rate } \\
\text { ratio }(95 \% \mathrm{Cl})\end{array}$} \\
\hline & With OH $(n=40)$ & Without OH $(n=324)$ & \\
\hline \multicolumn{4}{|c|}{ Generalised weakness } \\
\hline No & $33(10.3)$ & $287(89.7)$ & 1 \\
\hline Yes & $7(15.9)$ & $37(84.1)$ & $1.54(0.61-4.05)$ \\
\hline \multicolumn{4}{|l|}{ Nausea } \\
\hline No & $36(10.6)$ & $304(89.4)$ & 1 \\
\hline Yes & $4(16.7)$ & $20(83.3)$ & $1.57(0.61-4.05)$ \\
\hline \multicolumn{4}{|l|}{ Fall(s) } \\
\hline No & $30(9.9)$ & $272(90.1)$ & 1 \\
\hline Yes & $10(16.1)$ & $52(83.9)$ & $1.62(0.84-3.14)$ \\
\hline
\end{tabular}

*Difference is statistically significant $(p<0.05)$. BP: blood pressure; Cl: confidence interval

Table IV. Medical conditions and medications associated with orthostatic hypotension $(\mathrm{OH})(\mathrm{n}=364)$.

\begin{tabular}{|c|c|c|c|}
\hline \multirow[t]{2}{*}{ Parameter } & \multicolumn{2}{|c|}{ No. (\%) } & \multirow{2}{*}{$\begin{array}{l}\text { Prevalence rate } \\
\text { ratio }(95 \% \mathrm{Cl})\end{array}$} \\
\hline & With OH $(n=40)$ & Without $\mathrm{OH}(n=324)$ & \\
\hline \multicolumn{4}{|c|}{ Past medical history } \\
\hline \multicolumn{4}{|c|}{ Ischaemic heart disease } \\
\hline No & $33(10.3)$ & $287(89.7)$ & 1 \\
\hline Yes & 7 (15.9) & $37(84.1)$ & $1.54(0.73-3.27)$ \\
\hline \multicolumn{4}{|c|}{ Cardiac arrhythmia } \\
\hline No & $40(11.3)$ & $315(88.7)$ & 1 \\
\hline Yes & 0 & $9(100.0)$ & $0.40(0.03-6.07)$ \\
\hline \multicolumn{4}{|c|}{ Congestive cardiac failure } \\
\hline No & $37(10.5)$ & $317(89.5)$ & 1 \\
\hline Yes & $3(30.0)$ & $7(70.0)$ & $2.87(1.06-7.75)^{*}$ \\
\hline \multicolumn{4}{|c|}{ Hypertension } \\
\hline No & $5(11.1)$ & $40(88.9)$ & 1 \\
\hline Yes & $35(11.0)$ & $284(89.0)$ & $0.99(0.41-2.39)$ \\
\hline \multicolumn{4}{|c|}{ Diabetes mellitus } \\
\hline No & $23(9.6)$ & $217(90.4)$ & 1 \\
\hline Yes & $17(13.7)$ & $107(86.3)$ & $1.43(0.79-2.58)$ \\
\hline \multicolumn{4}{|c|}{ Dyslipidaemia } \\
\hline No & $3(4.9)$ & $58(95.1)$ & 1 \\
\hline Yes & $37(12.2)$ & $266(87.8)$ & $2.48(0.79-7.81)$ \\
\hline \multicolumn{4}{|l|}{ Stroke } \\
\hline No & $33(9.7)$ & $306(90.3)$ & 1 \\
\hline Yes & $7(28.0)$ & $18(72.0)$ & $2.87(1.42-5.85)^{*}$ \\
\hline \multicolumn{4}{|c|}{ Kidney disease } \\
\hline No & $32(9.8)$ & $293(90.2)$ & 1 \\
\hline Yes & $8(20.5)$ & $31(79.5)$ & $2.08(1.03-4.20)^{*}$ \\
\hline \multicolumn{4}{|l|}{ Arthritis } \\
\hline No & $40(11.3)$ & $314(88.7)$ & 1 \\
\hline Yes & 0 & $10(100.0)$ & $0.40(0.03-6.07)$ \\
\hline \multicolumn{4}{|c|}{ Fall(s) with hospitalisation } \\
\hline No & $39(10.9)$ & $318(89.1)$ & 1 \\
\hline Yes & $1(14.3)$ & $6(85.7)$ & $1.31(0.21-8.20)$ \\
\hline \multicolumn{4}{|c|}{ Osteoporosis } \\
\hline No & $40(11.0)$ & $322(89.0)$ & 1 \\
\hline Yes & 0 & $2(100.0)$ & $4.51(0.62-32.68)$ \\
\hline \multicolumn{4}{|c|}{ Medication history } \\
\hline \multicolumn{4}{|c|}{ Loop diuretic (e.g. frusemide) } \\
\hline No & $37(10.4)$ & $318(89.6)$ & 1 \\
\hline Yes & $3(33.3)$ & $6(66.7)$ & $3.19(1.21-8.47)^{*}$ \\
\hline
\end{tabular}




\begin{tabular}{|c|c|c|c|}
\hline \multirow[t]{2}{*}{ Parameter } & \multicolumn{2}{|c|}{ No. (\%) } & \multirow{2}{*}{$\begin{array}{l}\text { Prevalence rate } \\
\text { ratio }(95 \% \mathrm{Cl})\end{array}$} \\
\hline & With OH $(n=40)$ & Without OH $(n=324)$ & \\
\hline \multicolumn{4}{|c|}{$\begin{array}{l}\text { Thiazide diuretic } \\
\text { (e.g. hydrochlorothiazide) }\end{array}$} \\
\hline No & $31(10.0)$ & $279(90.0)$ & 1 \\
\hline Yes & $9(16.7)$ & $45(83.3)$ & $1.67(0.84-3.30)$ \\
\hline \multicolumn{4}{|c|}{ ACE inhibitor } \\
\hline No & $29(11.0)$ & 234 (89) & 1 \\
\hline Yes & $11(10.9)$ & $90(89.1)$ & $0.99(0.51-1.9)$ \\
\hline \multicolumn{4}{|c|}{ Angiotensin II receptor blocker } \\
\hline No & $33(11.1)$ & $263(88.9)$ & 1 \\
\hline Yes & $7(10.3)$ & $61(89.7)$ & $0.92(0.43-2.00)$ \\
\hline \multicolumn{4}{|c|}{ Beta-blocker } \\
\hline No & $20(9.7)$ & $186(90.3)$ & 1 \\
\hline Yes & $20(12.7)$ & $138(87.3)$ & $1.30(0.73-2.34)$ \\
\hline \multicolumn{4}{|c|}{ Calcium channel blocker } \\
\hline No & $19(11.9)$ & $140(88.1)$ & 1 \\
\hline Yes & $21(10.2)$ & $184(89.8)$ & $0.86(0.48-1.54)$ \\
\hline \multicolumn{4}{|c|}{ Alpha-blocker } \\
\hline No & $38(11.0)$ & $309(89.0)$ & 1 \\
\hline Yes & $2(11.8)$ & $15(88.2)$ & $1.07(0.28-4.08)$ \\
\hline \multicolumn{4}{|l|}{ Insulin } \\
\hline No & $39(11.1)$ & $313(88.9)$ & 1 \\
\hline Yes & $1(8.3)$ & $11(91.7)$ & $0.75(0.11-5.03)$ \\
\hline \multicolumn{4}{|l|}{ Metformin } \\
\hline No & $28(9.9)$ & $254(90.1)$ & 1 \\
\hline Yes & $12(14.6)$ & $70(85.4)$ & $1.47(0.78-2.77)$ \\
\hline \multicolumn{4}{|c|}{ Other oral hypoglycaemic agents } \\
\hline No & $31(10.3)$ & $269(89.7)$ & 1 \\
\hline Yes & $9(14.1)$ & $55(85.9)$ & $1.36(0.68-2.72)$ \\
\hline \multicolumn{4}{|l|}{ Sedative } \\
\hline No & $37(10.6)$ & $313(89.4)$ & 1 \\
\hline Yes & $3(21.4)$ & $11(78.6)$ & $2.03(0.71-5.78)$ \\
\hline \multicolumn{4}{|l|}{ Statin } \\
\hline No & $13(9.8)$ & $120(90.2)$ & 1 \\
\hline Yes & $27(11.7)$ & $204(88.3)$ & $1.20(0.64-2.24)$ \\
\hline \multicolumn{4}{|l|}{ Aspirin } \\
\hline No & $29(9.7)$ & $271(90.3)$ & 1 \\
\hline Yes & $11(17.2)$ & $53(82.8)$ & $1.78(0.94-3.37)$ \\
\hline \multicolumn{4}{|c|}{$\begin{array}{l}\text { Any antiplatelets (including } \\
\text { aspirin) }\end{array}$} \\
\hline No & $27(9.5)$ & $258(90.5)$ & 1 \\
\hline Yes & $13(16.5)$ & $66(83.5)$ & $1.74(0.94-3.21)$ \\
\hline \multicolumn{4}{|l|}{ Nitrates } \\
\hline No & $37(10.8)$ & $305(89.2)$ & 1 \\
\hline Yes & $3(13.6)$ & $19(86.4)$ & $1.26(0.42-3.77)$ \\
\hline
\end{tabular}

*Difference is statistically significant $(p<0.05)$. ACE: angiotensin-converting enzyme; $\mathrm{Cl}$ : confidence interval

two other factors we studied, are symptoms which can be attributed to dysregulation in the cardiovascular response; they are often secondary to impairment in the baroreflex, leading to a transient drop in cerebral blood flow when standing. ${ }^{(23)}$ However, we recognise that they are nonspecific symptoms with multifactorial causes, such as those related to patient medication, vestibular dysfunction, visual disturbances and disorders of the proprioception. $^{(24,25)}$

Medical conditions that affect circulation, such as congestive cardiac failure, stroke and kidney disease, were found to be associated with $\mathrm{OH}$ in our study, as several other studies have reported. ${ }^{(21,26,27)}$ Our resultsare compatible with Eigenbrodt et al's 
findings, which showed a similar association between $\mathrm{OH}$ and raised supine systolic and diastolic BP at baseline. ${ }^{(26)}$ Medications are important modifiable factors associated with $\mathrm{OH}^{(28)}$ In the present study, the use of loop diuretics was linked to the presence of $\mathrm{OH}$. Loop diuretics inhibit sodium and water reabsorption by the renal tubules, which in turn reduce left ventricular filling pressure, thereby reducing stroke volume and cardiac output via the Frank-Starling mechanism. ${ }^{(28)}$ Loop diuretics are also thought to cause dose-dependent vasodilatation by stimulating prostaglandin production in the renal and peripheral vasculature. ${ }^{(29)}$

This study highlighted several key determinants of $\mathrm{OH}$ to raise awareness of $\mathrm{OH}$ risk factors in the elderly among clinicians. $\mathrm{OH}$ will be a growing challenge given the rapidly ageing population in Singapore, leading to greater risks of falls and fractures, repeated or prolonged hospitalisations and increased care burden to the families. However, risk factors relating to medications such as loop diuretics are potentially modifiable. Clinicians should consider substituting such medications with alternatives if it is feasible for the respective patients. In line with efforts by the local health authority to promote active ageing, primary healthcare professionals should consistently encourage the elderly to take part in physical activity that is compatible with their fitness level, interests and environment. Policies that extend the retirement age should also favour engaging senior patients in the workforce, encouraging them to be more physically active to mitigate the adverse effects of $\mathrm{OH}$.

This study had its limitations. Firstly, its short recruitment period may have affected the representativeness of the target population; hence, care needs to be exercised in generalising the prevalence rate to the local elderly population. Next, the sample size was small and calculated using prevalence data from a foreign study. The power of the study was likely inadequate to examine the relationships among all the postulated risk factors (such as ethnicity) and $\mathrm{OH}$. Thus, we did not perform regression analysis of the statistically significant factors. It is likely that the factors that occurred more frequently in patients with $\mathrm{OH}$ were only associations and not necessarily causative; moreover, some of the associated factors were possibly a consequence of $\mathrm{OH}$, such as the use of walking aids and being inactive. Considering these limitations, the observations on risk factor associations should be interpreted with caution. However, this study can provide pilot data to design a future study that has adequate power to assess specific risk factors and develop interventions that target modifiable risk factors.

In conclusion, $11.0 \%$ of the elderly patients at a local polyclinic were affected by $\mathrm{OH}$. Comorbidity, and demographic, clinical and pharmacotherapeutic factors were associated with $\mathrm{OH}$. Some of these factors are modifiable and should be addressed by physicians managing these elderly patients.

\section{ACKNOWLEDGEMENTS}

The authors would like to thank Dr Alice Lai and A/Prof Tai Bee Choo from the Saw Swee Hock School of Public Health,
National University of Singapore, for their guidance; the staff of Geylang Polyclinic for their support, understanding and patience during the study; and the biostatistician at SingHealth Polyclinics, Ms Koh Yi Ling Eileen, and the team of medical students from the Yong Loo Lin School of Medicine, National University of Singapore, who contributed their time and effort to this study.

\section{REFERENCES}

1. Romero-Ortuno R, Cogan L, O'Shea D, Lawlor BA, Kenny RA. Orthostatic haemodynamics may be impaired in frailty. Age Ageing $2011 ; 40: 576-83$.

2. Consensus statement on the definition of orthostatic hypotension, pure autonomic failure, and multiple system atrophy. The Consensus Committee of the American Autonomic Society and the American Academy of Neurology. Neurology 1996; 46:1470.

3. Benvenuto LJ, Krakoff LR. Morbidity and mortality of orthostatic hypotension: implications for management of cardiovascular disease. Am J Hypertens 2011; 24:135-44.

4. Mehrabian S, Duron E, Labouree F, et al. Relationship between orthostatic hypotension and cognitive impairment in the elderly. J Neurol Sci 2010; 299:45-8.

5. Yap PL, Niti M, Yap KB, Ng TP. Orthostatic hypotension, hypotension and cognitive status: early comorbid markers of primary dementia? Dement Geriatr Cogn Disord 2008; 26:239-46.

6. Rutan GH, Hermanson B, Bild DE, et al. Orthostatic hypotension in older adults. The Cardiovascular Health Study. CHS Collaborative Research Group. Hypertension 1992; 19:508-19.

7. Tilvis RS, Hakala SM, Valvanne J, Erkinjuntti T. Postural hypotension and dizziness in a general aged population: a four-year follow-up of the Helsinki Aging Study. J Am Geriatr Soc 1996; 44:809-14.

8. Lagro J, Laurenssen NC, Schalk BW, et al. Diastolic blood pressure drop after standing as a clinical sign for increased mortality in older falls clinic patients. J Hypertens 2012; 30:1195-202.

9. van Nieuwenhuizen RC, van Dijk N, van Breda FG, et al; CAREFALL study group. Assessing the prevalence of modifiable risk factors in older patients visiting an ED due to a fall using the CAREFALL Triage Instrument. Am J Emerg Med 2010; 28:994-1001.

10. Protogerou AD, Stergiou GS, Lourida P, Achimastos A. Arterial stiffness and orthostatic blood pressure changes in untreated and treated hypertensive subjects. J Am Soc Hypertens 2008; 2:372-7.

11. Wu JS, Yang YC, Lu FH, Wu CH, Chang CJ. Population-based study on the prevalence and correlates of orthostatic hypotension/hypertension and orthostatic dizziness. Hypertens Res 2008; 31:897-904.

12. Siow BL. Postural hypotension in the elderly. Singapore Med J 1987; 28:338-41.

13. Low PA. Prevalence of orthostatic hypotension. Clin Auton Res 2008; 18 Suppl 1:8-13.

14. World Health Organization. Definition of an older or elderly person. Available at: http://www.who.int/healthinfo/survey/ageingdefnolder/en/ index.html. Accessed March 14, 2013.

15. Baliga R, Prabhu G. Orthostatic hypotension in healthy elderly: Is it a myth? N Am J Med Sci 2010; 2:416-8.

16. Hiitola P, Enlund H, Kettunen R, Sulkava R, Hartikainen S. Postural changes in blood pressure and the prevalence of orthostatic hypotension among home-dwelling elderly aged 75 years or older. J Hum Hypertens 2009; 23:33-9.

17. International Fund for Agricultural Development. Calculating the Sample Size. Available at: http://www.ifad.org/gender/tools/hfs/anthropometry/ ant_3.htm. Accessed March 14, 2013.

18. Kamaruzzaman S, Watt H, Carson C, Ebrahim S. The association between orthostatic hypotension and medication use in the British Women's Heart and Health Study. Age Ageing 2010; 39:51-6.

19. Poda R, Guaraldi P, Solieri L, et al. Standing worsens cognitive functions in patients with neurogenic orthostatic hypotension. Neurol Sci 2012; 33:469-73.

20. Department of Statistics Singapore. Latest data. Available at: http://www. singstat.gov.sg/statistics/latest-data\#15. Accessed July 19, 2016.

21. Fedorowski A, Engström G, Hedblad B, Melander O. Orthostatic hypotension predicts incidence of heart failure: the Malmö preventive project. Am J Hypertens 2010; 23:1209-15. 
22. Fedorowski A, Burri $\mathrm{P}$, Juul-Möller S, Melander O. A dedicated investigation unit improves management of syncopal attacks (Syncope Study of Unselected Population in Malmo--SYSTEMA I). Europace 2010; 12:1322-8.

23. Smit AA, Halliwill JR, Low PA, Wieling W. Pathophysiological basis of orthostatic hypotension in autonomic failure. J Physiol 1999; $519 \mathrm{Pt}$ 1:1-10.

24. Belal A Jr, Glorig A. Dysequilibrium of ageing (presbyastasis). J Laryngol Otol 1986; 100:1037-41.

25. Sloane PD, Baloh RW. Persistent dizziness in geriatric patients. J Am Geriatr Soc 1989; 37:1031-8
26. Eigenbrodt ML, Rose KM, Couper DJ, et al. Orthostatic hypotension as a risk factor for stroke: the atherosclerosis risk in communities (ARIC) study, 1987-1996. Stroke 2000; 31:2307-13.

27. Franceschini N, Rose KM, Astor BC, Couper D, Vupputuri S. Orthostatic hypotension and incident chronic kidney disease: the atherosclerosis risk in communities study. Hypertension 2010; 56:1054-9.

28. Milazzo V, Stefano CD, Servo S, et al. Drugs and Orthostatic Hypotension: Evidence from Literature. J Hypertens 2012; 1:104.

29. Pickkers P, Dormans TP, Russel FG, et al. Direct vascular effects of furosemide in humans. Circulation 1997; 96:1847-52. 